\title{
Impact of the COVID-19 Outbreak on Anesthesiologist Assistance for Endoscopic Procedures
}

\author{
Calcedonio Calcara ${ }^{1}$, Camilla Ciscato ${ }^{2}$, Arnaldo Amato ${ }^{3}$, Emanuele Sinagra ${ }^{4}$, Costanza Alvisi ${ }^{5}$, Sandro Ardizzone ${ }^{6}$, Andrea \\ Anderloni $^{7}$, and Pietro Gambitta ${ }^{1,2}$ : on behalf of the FISMAD Lombardy COVID-19 Impact on Anesthesiologist-Assisted \\ Endoscopy Study Group
}

${ }^{1}$ Endoscopy Unit, ASST Ovest Milanese, Magenta, Milan, ${ }^{2}$ Gastroenterology and Digestive Endoscopy Unit, ASST Ovest Milanese, Legnano, Milan, ${ }^{3}$ Gastroenterology Division, Valduce Hospital, Como, ${ }^{4}$ Gastroenterology and Endoscopy Unit, Institute Foundation G. Giglio, Cefalù, Palermo, ${ }^{5}$ Endoscopy Unit, Voghera and Vigevano Hospitals-ASST Pavia, Pavia, ${ }^{6}$ Gastroenterology and Endoscopy Unit, Fatebenefratelli-Sacco ASST, Milan, ${ }^{7}$ Division of Gastroenterology and Digestive Endoscopy, IRCCS Humanitas Research Hospital, Rozzano, Milan, Italy

Background/Aims: The coronavirus disease 2019 (COVID-19) outbreak has modified the activities of endoscopy units worldwide. Herein, we investigated the impact of the COVID-19 outbreak on anesthesiologist assistance for endoscopic procedures in Lombardy, Italy.

Methods: A questionnaire concerning anesthesiologist assistance provided from October 26 to December 6, 2020, in comparison with the same period in 2019, was sent to endoscopic units in Lombardy.

Results: Approximately 54\% (34/63) of the units responded. A reduction in the number of all endoscopies ( $-33.5 \%$; 18792 in 2020 vs. 28264 in 2019) and anesthesiologist-assisted endoscopies (-15.3\%; 2652 in 2020 vs. 3132 in 2019) was reported. A greater reduction in anesthesiologist assistance was observed in government community units (-29.5\%) than in academic (-14\%) and private community units (-4.6\%). Among all units, $85 \%$ reported a reduction in anesthesiologist assistance; 65\% observed a delay/ cancellation of procedures; $59 \%$, a restricted patient selection; $17 \%$, the need to transfer some patients to other hospitals; and $32 \%$, a related worsening of procedure quality.

Conclusion: The COVID-19 pandemic compromised the anesthesiologist assistance for endoscopic procedures in Lombardy, which worsened the procedure quality mainly in government community units. The COVID-19 "stress test" suggests a more balanced allocation of anesthesiologic resources in the future. Clin Endosc 2022;55:49-57

Key Words: Anesthesiologist assistance; COVID-19; Endoscopic quality

\section{INTRODUCTION}

The ongoing outbreak of coronavirus disease 2019 (COVID-19) has forced most hospitals to reallocate their resources to address the high flow of patients requiring intensive

Received: June 17, 2021 Revised: September 12, 2021

Accepted: September 24, 2021

Correspondence: Calcedonio Calcara

Ospedale Giuseppe Fornaroli, ASST Ovest Milanese Via al Donatore di Sangue, 50, Magenta, Milan 20013, Italy

Tel: +39-02-979631, Fax: +39-02-97963437, E-mail: ccalcara@libero.it

ORCID: https://orcid.org/0000-0002-7555-5380

(c) This is an Open Access article distributed under the terms of the Creative Commons Attribution Non-Commercial License (http://creativecommons.org/ licenses/by-nc/3.0) which permits unrestricted non-commercial use, distribution, and reproduction in any medium, provided the original work is properly cited. care. In this context, all the activities perceived as not essential, such as non-urgent surgical activities, were reduced in number or suspended, and a reallocation of many hospital resources was needed.

It has already been demonstrated that during the first wave of the COVID-19 outbreak, there was a large reduction in endoscopy unit (EU) activity, and most endoscopic procedures were forcefully deleted or postponed. ${ }^{1-4}$ Nevertheless, the impact of reallocation of anesthesiologic resources on EU activities is still unknown.

Therefore, we conducted a survey to investigate the impact of the COVID-19 outbreak on anesthesiologist assistance (AA) for endoscopic procedures in one of the most affected areas in Italy (Lombardy). 


\section{MATERIALS AND METHODS}

This study was a cross-sectional survey of general endoscopic activity and endoscopic procedures with AA performed from October 26 to December 6, 2020 in Lombardy (period of peak of infections, i.e., $>3000$ new positives each day in Lombardy, during the second phase of the COVID-19 outbreak), in comparison with the same period in 2019. A link to a structured web-based questionnaire with 18 items (Google Forms; Google LLC, Mountain View, CA, USA) (Supplementary Material 1 [SM1]) was sent by e-mail on December 23, 2020 to all $63 \mathrm{EU}$ members of the Italian Federation of Digestive Disease Societies - FISMAD. An e-mail, as well as a further telephone invitation, was sent every week in January to the EUs that did not respond or did not complete the questionnaire. Special efforts were made to enroll community EUs localized in small hospitals or that were performing a low number of procedures. Enrollment ended on January 31, 2021. Participation was voluntary, and no fees were applied.

In our analysis, categorical variables were summarized as frequencies and percentages.

Significant differences $(p<0.05)$ between the proportions of endoscopic procedures with and without AA were evaluated using the chi-squared test for categorical variables. Cramer's $V$ value was reported to demonstrate the strength of the dimension of the effect. All analyses were performed using the SPSS software (IBM SPSS Statistics for Windows, version 25.0; IBM Corp., Armonk, NY, USA).

\section{RESULTS}

Approximately 53.9\% (34/63) of the EUs responded to the questionnaire, and all the data were included in the analysis. The characteristics of the centers involved are summarized in Table 1. Before the COVID-19 pandemic, AA for endoscopic procedures was available only for high-risk patients (defined as patients with an American Society of Anesthesiology score of $>3)^{5}$ in $3 / 34$ (9\%) EUs, only for selected procedures in 12/34 (35\%) EUs, and only on established days in 10/34 EUs (29\%) and was available daily in 9/34 EUs (26\%) (SM1; answer 3).

A reduction of $33.5 \%$ in the overall number of endoscopic procedures (18792 procedures in 2020 vs. 28264 procedures in 2019 ) and $15.3 \%$ in the number of endoscopic procedures with AA (2652 procedures with AA in 2020 vs. 3132 procedures with AA in 2019) was observed. The difference between the numbers of endoscopic procedures with and without AA performed in 2020 and 2019 was significant $(p=0.001)$ (Table 2A).

An overall reduction of $36 \%$ in the number of routine esophagogastroduodenoscopies (EGDs) and colonoscopies (15906 non-urgent routine endoscopies in 2020 vs. 24830 in 2019) was observed, with a significant difference (19.5\%, $p=0.001$ ) found when compared with the number of procedures with AA (1187 non-urgent routine procedures with AA in 2020 vs. 1474 in 2019). The number of urgent upper and lower endoscopies (defined as outpatient procedures needing to be performed within 72 hours according to the statement of

Table 1. Main Characteristics of the Endoscopic Units Enrolled and Usual Location of Procedures with Anesthesiologist Assistance

\begin{tabular}{lc}
\hline & Number of endoscopic units \\
\hline Overall endoscopic units & $34 / 63$ \\
Government community hospitals & $20 / 34$ \\
Private community hospitals & $7 / 34$ \\
Academic hospitals & $7 / 34$ \\
$<1000$ procedures/year & $0 / 34$ \\
$<3000$ procedures/year & $6 / 34$ \\
$>3000$ procedures/year & $28 / 34$ \\
Endoscopic units performing ERCP & $27 / 34$ \\
Endoscopic units performing endoscopic ultrasonography & $16 / 34$ \\
Procedures with AA in endoscopy room only & $15 / 34$ \\
Procedures with AA in surgical room only & $6 / 34$ \\
Procedures with AA in either locations & $13 / 34$ \\
Procedures with AA in emergency room & $0 / 34$ \\
\hline
\end{tabular}

Data are presented as number.

AA, anesthesiologist assistance; ERCP, endoscopic retrograde cholangiopancreatography. 
the Lombardy government ${ }^{6}$ or as inpatient procedures needing to be performed within 24 hours) ${ }^{7-10}$ was reduced by $17 \%$ (782 urgent upper and lower endoscopies in 2020 vs. 942 in 2019), with a reduction of only $2.9 \%$ when compared with the number of procedures with AA (284 urgent upper and lower endoscopies with AA in 2020 vs. 290 in 2019). Similarly, the Delta between the procedures with and without AA in 2020 and 2019 was found to be significant $(p=0.015)$. There was a reduction in the number of overall advanced/interventional procedures (i.e., endoscopic retrograde cholangiopancreatography $[\mathrm{ERCP}][-24 \%]$ and enteral stent placement, endoscopic submucosal dissection, and gastrointestinal dilations [-10.5\%]) (Table 2B). A reduction of $38.5 \%$ was also observed in the number of procedures with AA routinely performed exclusively or even in the operating room suite (56\% of the EUs) in 2020. Meanwhile, a reduction of only $7.6 \%$ was observed in the number of procedures with AA performed in endoscopic rooms only (Table 2C).

In the subgroup analysis, the government community EUs declared a reduction in the overall number of endoscopies by 39\% (9351 endoscopies in 2020 vs. 15360 in 2019) and in the overall number of endoscopies with AA by $29.5 \%$ (549 endoscopies with AA in 2020 vs. 779 in 2019); the private community EUs declared a reduction in the overall number of endoscopies by $25.5 \%$ (3879 endoscopies in 2020 vs. 5207 in 2019) and in the overall number endoscopies with AA by $4.6 \%(800$ endoscopies with AA in 2020 vs. 839 in 2019); the academic community EUs declared a reduction in the overall number of endoscopies by $27.7 \%$ (5562 endoscopies in 2020 vs. 7697 in 2019) and in the overall number of endoscopies with AA by $14 \%$ (1303 endoscopies with AA in 2020 vs. 1514 in 2019). The Delta between the endoscopies with and without AA in 2020 and 2019 was significant in all subgroups $(p=0.002$, $p=0.001$, and $p=0.001$, respectively) (Table 2A). The activities in the government, private, and academic community EUs are reported in detail in Table 3.

Moreover, we explored the specific settings of ERCP, a procedure that should preferably be performed with AA. A reduction in the overall number of ERCP by $24 \%$ (579 ERCP in 2020 vs. 762 in 2019) and in the overall number of ERCP with AA by $21 \%$ (391 ERCP with AA in 2020 vs. 495 in 2019) was observed. The percentage of ERCP with AA was $67.5 \%$ in 2020 and 65\% in 2019. The Delta between the ERCPs with and without AA in 2020 and 2019 was not found to be significant (Table 2B). However, among only the government community EUs, a reduction of $28.3 \%$ in the overall number of ERCP (278 ERCP in 2020 vs. 388 in 2019) and 36.9\% in the overall number of ERCP with AA (171 ERCP with AA in 2020 vs. 271 in 2019) was observed. The percentage of ERCP with AA in the government community EUs decreased from $69.8 \%$ in 2019 to $61.5 \%$ in 2020. The Delta between the ERCPs with and without AA in 2020 and 2019 was significant $(p=0.001)$ (Table 3A).

From October 26 to December 6, 2020, 188/579 (32.5\%) ERCPs were performed without AA. Interestingly, 30 (16\%) of these 188 ERCPs were interrupted or needed a change of plan owing to patient intolerance/criticity; this affected the quality of ERCP in 10/27 (37\%) EUs (SM1; answer 18). The decision to perform ERCP without AA was based on internal guidelines (SM1; answer 16) in 6/27 (22.2\%) EUs and on the discretion of the gastroenterologist, without any preliminary anesthesiologic evaluation, in 13/27 (48.1\%) EUs (SM1; answer 16). Moreover, $7 / 27$ (25.9\%) EUs were constrained to a variable percentage of ERCP without AA (SM1; answer 16).

Furthermore, our questionnaire contained a "not quantitative" section, in which the respondents were asked about critical issues and perceptions related to AA for endoscopic procedures. A total of 29/34 (85.2\%) EUs declared a reduced or absent AA (SM1; answer 9). In particular, the number of EUs performing procedures with AA only for high-risk patients increased from $3 / 34$ (9\%) in 2019 to $7 / 34(20 \%)$ in 2020; meanwhile, the number of EUs incorporating AA only for selected procedures decreased from 12/34 (35\%) in 2019 to $9 / 34$ $(26 \%)$ in 2020. Moreover, there was an overall reduction in the number of slots for procedures with AA in 10/34 (29\%) EUs and an increased difficulty of planning any procedure with AA for any type of patient in 13/34 (38\%) EUs (SM1; answer 11). Furthermore, 22/34 (64.7\%) EUs declared that they had to postpone some procedures indefinitely or to cancel them in consequence of reduction of AA (SM1; answer 13); 20/34 (58.8\%) EUs had to exclude some patients from undergoing procedures with AA by selecting frail patients (SM1; answer 14); 6/34 (17.6\%) EUs had to transfer some patients to another hospital owing to the reduction of AA on site (SM1; answer 12); and finally, 11/34 (32.3\%) EUs declared a worsening of the quality of procedures owing to the reduction of AA, reported as reduction in the number of successful procedures, lower patient tolerability, or prolonged duration of procedures. The number of sedation-related complications was not reported to have increased (SM1; answer 17).

A total of 26/34 (76.5\%) EUs declared that they did not have internal guidelines regarding the appropriate request of AA for endoscopic procedures; only one unit introduced an internal guideline as a consequence of the COVID-19 outbreak (SM1; answer 15). Other services and activities in the hospitals included in our survey were also affected by the limited availability of AA, particularly elective non-oncological surgery in 27/34 EUs and other outpatient activities in 18/34 EUs (SM1; answer 10). 
Table 2

(A) Comparation between Procedures with and without Anesthesiologist Assistance in 2019 and in 2020 Stratified According to the Type and the Volume of the Endoscopic Units Enrolled

\begin{tabular}{|c|c|c|c|c|c|c|c|c|c|c|c|}
\hline Variable & $\begin{array}{l}\text { With } \\
\text { AA } \\
2019\end{array}$ & $\begin{array}{l}\text { With- } \\
\text { out AA } \\
2019\end{array}$ & $\begin{array}{l}\text { Total } \\
2019^{a}\end{array}$ & $\begin{array}{l}\text { With } \\
\text { AA } \\
2020\end{array}$ & $\begin{array}{l}\text { With- } \\
\text { out AA } \\
2020\end{array}$ & $\begin{array}{l}\text { Total } \\
2020^{b}\end{array}$ & $\begin{array}{l}\text { Chi- } \\
\text { squared } \\
\text { test }\end{array}$ & $\begin{array}{c}P \\
\text { value }\end{array}$ & $\begin{array}{l}\text { Cra- } \\
\text { mer's } \\
V\end{array}$ & $\begin{array}{c}\text { Delta } \\
\%^{\mathrm{c}}\end{array}$ & $\begin{array}{l}\text { Delta } \\
\text { procedures } \\
\text { with AA \% }{ }^{d}\end{array}$ \\
\hline Overall endoscopic procedures & 3132 & 25132 & 28264 & 2652 & 16140 & 18792 & 96.2 & 0.001 & 0.045 & $-33.5 \%$ & $-15.3 \%$ \\
\hline $\begin{array}{l}\text { Endoscopic procedures in government } \\
\text { community hospitals }\end{array}$ & 779 & 14581 & 15360 & 549 & 8802 & 9351 & 9.1 & 0.002 & 0.019 & $-39 \%$ & $-29.5 \%$ \\
\hline $\begin{array}{l}\text { Endoscopic procedures in private } \\
\text { community hospitals }\end{array}$ & 839 & 4368 & 5207 & 800 & 3079 & 3879 & 30.6 & 0.001 & 0.058 & $-25.5 \%$ & $-4.6 \%$ \\
\hline $\begin{array}{l}\text { Endoscopic procedures in academic } \\
\text { hospitals (private and government) }\end{array}$ & 1514 & 6183 & 7697 & 1303 & 4259 & 5562 & 27.2 & 0.001 & 0.045 & $-27.7 \%$ & $-14 \%$ \\
\hline $\begin{array}{l}\text { Endoscopic procedures in endoscopic } \\
\text { units with }>3000 \text { patients/year }\end{array}$ & 2671 & 22792 & 25463 & 2288 & 14515 & 16803 & 95.5 & 0.001 & 0.048 & $-34 \%$ & $-14.3 \%$ \\
\hline $\begin{array}{l}\text { Endoscopic procedures in endoscopic } \\
\text { units with }<3000 \text { patients/year }\end{array}$ & 461 & 2340 & 2801 & 364 & 1625 & 1989 & 2.7 & NS & 0.024 & $-29 \%$ & $-21 \%$ \\
\hline
\end{tabular}

${ }^{\text {a) }}$ from October 26 to December 6, 2019. ${ }^{\text {b) }}$ from October 26 to December $6,2020 .{ }^{c}$ referred to variation between total procedures. ${ }^{\text {d) }}$ referred to variation between total procedures with anesthesiologist assistance.

Data are presented as number.

AA, anesthesiologist assistance; NS, not significant.

(B) Comparation between Procedures with and without Anesthesiologist Assistance in 2019 and in 2020 Stratified According to the Type of the Procedure in All Endoscopic Units

\begin{tabular}{|c|c|c|c|c|c|c|c|c|c|c|c|}
\hline Variable & $\begin{array}{c}\text { With } \\
\text { AA } \\
2019\end{array}$ & $\begin{array}{c}\text { With- } \\
\text { out AA } \\
2019\end{array}$ & $\begin{array}{l}\text { Total } \\
2019^{\mathrm{a}}\end{array}$ & $\begin{array}{c}\text { With } \\
\text { AA } \\
2020\end{array}$ & $\begin{array}{c}\text { With- } \\
\text { out AA } \\
2020\end{array}$ & $\begin{array}{l}\text { Total } \\
2020^{b}\end{array}$ & $\begin{array}{c}\text { Chi- } \\
\text { squared } \\
\text { test }\end{array}$ & $\begin{array}{c}P \\
\text { value }\end{array}$ & $\begin{array}{c}\text { Cra- } \\
\text { mer's } \\
V\end{array}$ & $\begin{array}{c}\text { Delta } \\
\%^{c}\end{array}$ & $\begin{array}{c}\text { Delta } \\
\text { procedures } \\
\text { with AA } \%^{\mathrm{d}}\end{array}$ \\
\hline $\begin{array}{l}\text { Not urgent upper and lower endosco- } \\
\text { pies (EGDs and colonoscopies) }\end{array}$ & 1474 & 23356 & 24830 & 1187 & 14719 & 15906 & 36.9 & 0.001 & 0.03 & $-36 \%$ & $-19.5 \%$ \\
\hline $\begin{array}{l}\text { Urgent upper and lower endoscopies } \\
\text { (EGDs and colonoscopies) }\end{array}$ & 290 & 652 & 942 & 284 & 498 & 782 & 5.8 & 0.015 & 0.058 & $-17 \%$ & $-2.9 \%$ \\
\hline EUS & 449 & 487 & 936 & 408 & 429 & 837 & 1.9 & NS & 0.033 & $-10.6 \%$ & $-9 \%$ \\
\hline ERCP & 495 & 267 & 762 & 391 & 188 & 579 & 0.97 & NS & 0.027 & $-24 \%$ & $-21 \%$ \\
\hline PEG & 133 & 76 & 209 & 111 & 53 & 164 & 0.66 & NS & 0.042 & $-21.6 \%$ & $-16.5 \%$ \\
\hline $\begin{array}{l}\text { Other procedures (enteral stents, ESD, } \\
\text { dilations and others) }\end{array}$ & 291 & 294 & 585 & 271 & 253 & 524 & 0.141 & NS & 0.009 & $-10.5 \%$ & $-6.8 \%$ \\
\hline
\end{tabular}

${ }^{a)}$ from October 26 to December 6, 2019. ${ }^{\text {b) }}$ from October 26 to December 6, 2020. ${ }^{\text {c) }}$ referred to variation between total procedures. ${ }^{\mathrm{d})}$ referred to variation between total procedures with anesthesiologist assistance.

Data are presented as number.

AA, anesthesiologist assistance; EGD, esophagogastroduodenoscopy; ERCP, endoscopic retrograde cholangiopancreatography; ESD, endosocopic submucosal dissection; EUS, endoscopoic ultrasonography; NS, not significant; PEG, percutaneous endoscopic gastrostomy.

(C) Comparation between Procedures with and without Anesthesiologist Assistance in 2020 Stratified According to Location of Anesthesiologist Assistance (Endoscopic Room vs. Operation Room)

\begin{tabular}{|c|c|c|c|c|c|c|c|c|c|c|c|}
\hline Variable & $\begin{array}{c}\text { With } \\
\text { AA } \\
2019 \\
\end{array}$ & $\begin{array}{c}\text { With- } \\
\text { out AA } \\
2019\end{array}$ & $\begin{array}{l}\text { Total } \\
2019^{\mathrm{a}}\end{array}$ & $\begin{array}{c}\text { With } \\
\text { AA } \\
2020\end{array}$ & $\begin{array}{c}\text { With- } \\
\text { out AA } \\
2020\end{array}$ & $\begin{array}{l}\text { Total } \\
2020^{b}\end{array}$ & $\begin{array}{c}\text { Chi- } \\
\text { squared } \\
\text { test }\end{array}$ & $\begin{array}{c}P \\
\text { value }\end{array}$ & $\begin{array}{c}\text { Cra- } \\
\text { mer's } \\
V\end{array}$ & $\begin{array}{l}\text { Delta } \\
\%^{c}\end{array}$ & $\begin{array}{c}\text { Delta } \\
\text { procedures } \\
\text { with AA \% }\end{array}$ \\
\hline $\begin{array}{l}\text { Endoscopic units performing AA only } \\
\text { in endoscopic room }(\mathrm{N}=15)\end{array}$ & 2350 & 10877 & 13227 & 2171 & 6732 & 8903 & 144 & 0.001 & 0.81 & $-32.7 \%$ & $-7.6 \%$ \\
\hline $\begin{array}{l}\text { Endoscopic units performing AA only } \\
\text { or also in surgical room }(\mathrm{N}=19)\end{array}$ & 782 & 14255 & 15037 & 481 & 9408 & 9889 & 1.4 & NS & 0.008 & $-34.3 \%$ & $-38.5 \%$ \\
\hline
\end{tabular}

${ }^{a)}$ from October 26 to December 6, 2019. ${ }^{\text {b) }}$ from October 26 to December 6, 2020. ${ }^{c)}$ referred to variation between total procedures. ${ }^{d)}$ referred to variation between total procedures with anesthesiologist assistance.

Data are presented as number.

AA, anesthesiologist assistance; EUS, endoscopoic ultrasonography; N, number; NS, not significant. 
Table 3

(A) Comparation between Procedures with and without Anesthesiologist Assistance in 2019 and in 2020 Stratified According to the Type of the Procedure in Government Community Endoscopic Units

\begin{tabular}{|c|c|c|c|c|c|c|c|c|c|c|c|}
\hline Variable & $\begin{array}{c}\text { With } \\
\text { AA } \\
2019\end{array}$ & $\begin{array}{l}\text { With- } \\
\text { out } \\
\text { AA } \\
2019\end{array}$ & $\begin{array}{l}\text { Total } \\
2019^{a}\end{array}$ & $\begin{array}{c}\text { With } \\
\text { AA } \\
2020\end{array}$ & $\begin{array}{l}\text { With- } \\
\text { out } \\
\text { AA } \\
2020\end{array}$ & $\begin{array}{l}\text { Total } \\
2020^{b}\end{array}$ & $\begin{array}{c}\text { Chi- } \\
\text { squared } \\
\text { test }\end{array}$ & $\begin{array}{c}P \\
\text { value }\end{array}$ & $\begin{array}{l}\text { Cram- } \\
\text { er's } V\end{array}$ & $\begin{array}{c}\text { Delta } \\
\%^{c}\end{array}$ & $\begin{array}{c}\text { Delta } \\
\text { procedures } \\
\text { with } \mathrm{AA}^{\mathrm{b}} \\
\%^{\mathrm{d}}\end{array}$ \\
\hline $\begin{array}{l}\text { Not urgent upper and lower endos- } \\
\text { copies (EGDs and colonoscopies) }\end{array}$ & 245 & 13592 & 13837 & 133 & 8023 & 8156 & 0.59 & NS & 0.005 & $-41 \%$ & $-45.8 \%$ \\
\hline $\begin{array}{l}\text { Urgent upper and lower endoscopies } \\
\text { (EGDs and colonoscopies) }\end{array}$ & 97 & 368 & 465 & 115 & 267 & 382 & 9.5 & 0.002 & 0.106 & $-17.5 \%$ & $+18.5 \%$ \\
\hline EUS & 16 & 351 & 367 & 21 & 313 & 334 & 1.3 & NS & 0.043 & $-9 \%$ & $+31.2 \%$ \\
\hline ERCP & 271 & 117 & 388 & 171 & 107 & 278 & 64.8 & 0.001 & 0.312 & $-28.3 \%$ & $-36.9 \%$ \\
\hline PEG & 73 & 52 & 125 & 60 & 28 & 88 & 2.1 & NS & 0.099 & $-29.6 \%$ & $-17.8 \%$ \\
\hline $\begin{array}{l}\text { Other procedures (enteral stents, } \\
\text { ESD, dilations and others) }\end{array}$ & 77 & 101 & 178 & 49 & 64 & 113 & 0.000 & NS & 0.001 & $-36.5 \%$ & $-36.4 \%$ \\
\hline
\end{tabular}

${ }^{a)}$ from October 26 to December 6, 2019. ${ }^{\text {b) }}$ from October 26 to December 6, 2020. ${ }^{\text {c) }}$ referred to variation between total procedures. ${ }^{\text {d) }}$ referred to variation between total procedures with anesthesiologist assistance.

Data are presented as number.

AA, anesthesiologist assistance; EGD, esophagogastroduodenoscopy; ERCP, endoscopic retrograde cholangiopancreatography; ESD, endosocopic submucosal dissection; EUS, endoscopoic ultrasonography; NS, not significant; PEG, percutaneous endoscopic gastrostomy.

(B) Comparation between Procedures with and without Anesthesiologist Assistance in 2019 and in 2020 Stratified According to the Type of the Procedure in Private Community Endoscopic Units

\begin{tabular}{|c|c|c|c|c|c|c|c|c|c|c|c|}
\hline Variable & $\begin{array}{c}\text { With } \\
\text { AA } \\
2019\end{array}$ & $\begin{array}{c}\text { With- } \\
\text { out } \\
\text { AA } \\
2019\end{array}$ & $\begin{array}{l}\text { Total } \\
2019^{\mathrm{a}}\end{array}$ & $\begin{array}{c}\text { With } \\
\text { AA } \\
2020\end{array}$ & $\begin{array}{c}\text { With- } \\
\text { out } \\
\text { AA } \\
2020\end{array}$ & $\begin{array}{l}\text { Total } \\
2020^{b}\end{array}$ & $\begin{array}{c}\text { Chi- } \\
\text { squared } \\
\text { test }\end{array}$ & $\begin{array}{c}P \\
\text { value }\end{array}$ & $\begin{array}{l}\text { Cram- } \\
\text { er's } V\end{array}$ & $\begin{array}{c}\text { Delta } \\
\%^{c}\end{array}$ & $\begin{array}{c}\text { Delta } \\
\text { procedures } \\
\text { with } \mathrm{AA}^{\mathrm{b}} \\
\%^{\mathrm{d}}\end{array}$ \\
\hline $\begin{array}{l}\text { Not urgent upper and lower endos- } \\
\text { copies (EGDs and colonoscopies) }\end{array}$ & 642 & 4197 & 4839 & 613 & 2950 & 3563 & 54.5 & 0.001 & 0.078 & $-26.4 \%$ & $-4.5 \%$ \\
\hline $\begin{array}{l}\text { Urgent upper and lower endoscopies } \\
\text { (EGDs and colonoscopies) }\end{array}$ & 59 & 84 & 143 & 42 & 78 & 120 & 1.1 & NS & 0.064 & $-16 \%$ & $-28.8 \%$ \\
\hline EUS & 68 & 51 & 119 & 60 & 38 & 98 & 0.37 & NS & 0.041 & $-17.7 \%$ & $-11.7 \%$ \\
\hline ERCP & 34 & 26 & 60 & 43 & 0 & 43 & 36.4 & 0.001 & 0.594 & $-28.3 \%$ & $+26 \%$ \\
\hline PEG & 20 & 7 & 27 & 16 & 7 & 23 & 0.125 & NS & 0.05 & $-14.8 \%$ & $-20 \%$ \\
\hline $\begin{array}{l}\text { Other procedures (enteral stents, } \\
\text { ESD, dilations and others) }\end{array}$ & 16 & 3 & 19 & 26 & 6 & 32 & 0.08 & NS & 0.038 & $+68 \%$ & $+62 \%$ \\
\hline
\end{tabular}

${ }^{a)}$ from October 26 to December 6, 2019. ${ }^{\text {b) }}$ from October 26 to December 6, 2020. ${ }^{c)}$ referred to variation between total procedures. ${ }^{\text {d) }}$ referred to variation between total procedures with anesthesiologist assistance.

Data are presented as number.

AA, anesthesiologist assistance; EGD, esophagogastroduodenoscopy; ERCP, endoscopic retrograde cholangiopancreatography; ESD, endosocopic submucosal dissection; EUS, endoscopoic ultrasonography; NS, not significant; PEG, percutaneous endoscopic gastrostomy. 
(C) Comparation between Procedures with and without Anesthesiologist Assistance in 2019 and in 2020 Stratified According to the Type of the Procedure in Academic Endoscopic Units (Government and Private)

\begin{tabular}{|c|c|c|c|c|c|c|c|c|c|c|c|}
\hline Variable & $\begin{array}{c}\text { With } \\
\text { AA } \\
2019\end{array}$ & $\begin{array}{c}\text { With- } \\
\text { out } \\
\text { AA } \\
2019\end{array}$ & $\begin{array}{r}\text { Total } \\
2019^{A}\end{array}$ & $\begin{array}{c}\text { With } \\
\text { AA } \\
2020\end{array}$ & $\begin{array}{c}\text { With- } \\
\text { out } \\
\text { AA } \\
2020\end{array}$ & $\begin{array}{l}\text { Total } \\
2020^{b}\end{array}$ & $\begin{array}{c}\text { Chi- } \\
\text { squared } \\
\text { test }\end{array}$ & $\begin{array}{c}P \\
\text { value }\end{array}$ & $\begin{array}{l}\text { Cram- } \\
\text { er's } V\end{array}$ & $\begin{array}{c}\text { Delta } \\
\%^{\mathrm{c}}\end{array}$ & $\begin{array}{c}\text { Delta } \\
\text { procedures } \\
\text { with } \mathrm{AA}^{\mathrm{b}} \\
\%^{\mathrm{d}}\end{array}$ \\
\hline $\begin{array}{l}\text { Not urgent upper and lower endosco- } \\
\text { pies (EGDs and colonoscopies) }\end{array}$ & 587 & 5567 & 6154 & 441 & 3746 & 4187 & 2.7 & NS & 0.16 & $-31.96 \%$ & $-24.8 \%$ \\
\hline $\begin{array}{l}\text { Urgent upper and lower endoscopies } \\
\text { (EGDs and colonoscopies) }\end{array}$ & 134 & 200 & 334 & 127 & 153 & 280 & 1.7 & NS & 0.053 & $-16.17 \%$ & $-5.2 \%$ \\
\hline EUS & 365 & 85 & 450 & 327 & 78 & 405 & 0.019 & NS & 0.005 & $-10 \%$ & $-10.4 \%$ \\
\hline ERCP & 190 & 124 & 314 & 177 & 81 & 258 & 4.1 & 0.045 & 0.084 & $-17.8 \%$ & $-6.8 \%$ \\
\hline PEG & 40 & 17 & 57 & 35 & 18 & 53 & 0.217 & NS & 0.044 & $-7 \%$ & $-12.5 \%$ \\
\hline $\begin{array}{l}\text { Other procedures (enteral stents, ESD, } \\
\text { dilations and others) }\end{array}$ & 198 & 190 & 388 & 196 & 183 & 379 & 0.036 & NS & 0.007 & $-2.3 \%$ & $-1 \%$ \\
\hline
\end{tabular}

a) from October 26 to December 6, 2019. ${ }^{\text {b) }}$ from October 26 to December 6, 2020. ${ }^{c}$ referred to variation between total procedures. ${ }^{\text {d) }}$ referred to variation between total procedures with anesthesiologist assistance.

Data are presented as number.

AA, anesthesiologist assistance; EGD, esophagogastroduodenoscopy; ERCP, endoscopic retrograde cholangiopancreatography; ESD, endosocopic submucosal dissection; EUS, endoscopoic ultrasonography; NS, not significant; PEG, percutaneous endoscopic gastrostomy.

\section{DISCUSSION}

This multi-center survey demonstrated a meaningful reduction in AA for endoscopic procedures during the second wave of the COVID-19 pandemic in Lombardy.

The need for sedation and the decision on the setting of the procedure performance were generally influenced by patient-related and/or procedure-related conditions, ${ }^{11-13}$ ranging from mild to moderate sedation to deep sedation or from general anesthesia located in the endoscopic room to the operating room. ${ }^{14,15}$ Considering that digestive endoscopy in recent years has increased its range of action as well as its complexity, adequate sedation during procedures has become necessary. Moreover, since in certain countries, such as Italy, only anesthesiologists are allowed to use medications needed to obtain deeper levels of sedation (i.e., propofol), their presence is essential to allow proper execution of procedures. However, the increased demand for AA often clashes with the difficulty of having dedicated staff for endoscopy services owing to organizational changes or an inadequate perception of the need for AA. ${ }^{14-16}$

A recent Italian survey documented that the COVID-19 outbreak has yielded a strong reduction in activities in 40 of 41 involved EUs. ${ }^{2}$ The number of fast-track procedures was reduced by $53.6 \%$ in March to April 2020 compared with that in the same period in 2019. ${ }^{17}$ Even the number of urgent endoscopies has decreased during the COVID-19 outbreak. ${ }^{18}$ Similarly, most of the EUs that participated in our survey had to change their routine practice, both in terms of the total number of slots available for endoscopic procedures with AA and being forced to change the normal selection of patients and procedures to be performed with AA. Consequently, the delay or cancelation of some procedures or the need to transfer patients to different centers became necessary. This yielded a reduction in the quality of the procedures, described as a reduction in the percentage of success, a lower patient tolerability, or a prolonged duration of procedures in approximately one-third of the EUs (SM1; answer 17). Moreover, 37\% of the EUs acknowledged a reduction in the quality parameters of ERCP, described as interruption of the procedure or a change in the procedure plan owing to patient intolerance/criticity in relation to the absence of AA (SM1; answer 18).

We observed a reduction in the number of urgent endoscopies during the period analyzed compared with the number observed during the same period in 2019. This confirmed previous data referring to the first wave of the pandemic. ${ }^{18}$ Interestingly, the rate of urgent procedures with AA was not negatively affected in any of the three EU typologies analyzed in our study. This finding is reassuring, as it shows that AA for critical patients has been preserved in an urgent context.

We also found a high discrepancy in the AA data related to the location where the endoscopist performed the procedures. 
Indeed, a greater reduction was observed when the procedures with AA were routinely performed exclusively or even in the operating room suite (56\% of the EUs, $-38.5 \%$ of the procedures with $\mathrm{AA}$ ) than when the procedures with $\mathrm{AA}$ were performed in the endoscopic room only ( $44 \%$ of the EUs, $-7.6 \%$ of the procedures with AA) (Table 2C). The resources available in the operating room are generally shared among healthcare staff, including surgeons, gynecologists, and ear, nose and throat specialists, a well-known risk condition called "the tragedy of the commons." However, it is reassuring that urgent esophagogastroduodenoscopies and colonoscopies with AA were also preserved in the subgroup of EUs performing procedures with AA in the operating room suite (134 procedures in 2020 vs 129 in 2019).

A non-homogeneous reduction in activity was observed in the analysis of the different types of EUs. Indeed, the reduction was very impressive for the EUs located in government community hospitals. In general, the difference between the EUs located in government and private community hospitals was more evident for non-urgent esophagogastroduodenoscopies and colonoscopies with AA and for ERCP with AA (-45.8\% and $-36.9 \%$ vs. $-4.5 \%$ and $+26 \%$, respectively). Only $1 / 20(5 \%)$ government community EU declared no reduction in AA for endoscopic procedures; whereas 4/14 (28\%) private and academic community EUs were not affected by this reduction. We do not have certain data on the fact that the government community hospitals included in the survey were more affected by the COVID-19 outbreak than the private or academic community hospitals. Similarly, the administrative policies of the Lombardy government, a different internal organization, and the available resources could explain the difference in the endoscopic activity and AA data recorded in the survey.

The first wave of the COVID-19 pandemic yielded a collapse of intensive care units (ICUs). In March 2020, the risk of death or survival in Lombardy as well as in many other places in the world was uncertain ${ }^{20}$ owing to the high discrepancy between resources and requests, ${ }^{21}$ with rationing of ventilators and anesthesiologist care. ${ }^{22,23-25}$ When poor resources are available to cope with an emergency, rigid and transparent guidelines for prioritization are needed to overcome the differences in hospital care and inequity. ${ }^{26-28}$ Unfortunately, a comprehensive organization of anesthesiologist' resources in Lombardy was lacking or inadequate and, despite the findings of our survey should be interpreted cautiously, a discrimination risk also persisted during the second wave and may be ongoing. In the first wave, the peak of access to ICUs in Lombardy was observed on April 3, 2020 (1381 patients); this number of patients was sharply higher than that in the second wave peak on November 22, 2020 (942 patients, -31.3\%). ${ }^{29,30}$ However, during the second wave, our data demonstrated a reduction in
AA for endoscopic procedures as well as for surgical activities.

With regard to the selection of patients who required $\mathrm{AA}$ for endoscopic procedures, although position papers endorsed by anesthesiologist and gastroenterologist societies are available, ${ }^{14-16}$ only a quarter of the EUs included in our survey declared to have had internal guidelines for this purpose, and only one unit was forced to introduce an internal guideline for the COVID-19 outbreak. The decision to perform procedures without AA not based on a standardized strategy by internal guidelines may have led to a lower quality of the procedures.

Our study has some limitations. Since it had a retrospective design, and it was a regional survey limited to a precise period, the study could not portray a comprehensive and broad image of AA for endoscopic procedures during the COVID-19 pandemic. Moreover, some questions in the questionnaire were "qualitative," and the answers could not be precisely analyzed. Nevertheless, our study also has some strengths. A high percentage of EUs in a representative Western European region was enrolled. In addition, the topic was analyzed deeply, with quantitative and qualitative answers.

It is certainly not our intention to argue that the pandemic should or could be handled differently. It is obvious that in the presence of limited resources, priority must be given to patients with the most urgent needs and that AA for endoscopic procedures certainly is not among the priority activities in this pandemic. However, we observed a worsening of procedure quality owing to the reduction in AA in more than $30 \%$ of the centers (SM1; answer 17). Therefore, we believe that during this period, in which there is partial unavailability of AA, how gastroenterologists and anesthesiologists should resume normal activities at the end of the emergency should be reflected upon to improve the quality of the services offered to patients, especially the most fragile populations.

\section{Conflicts of Interest}

The authors have no potential conflicts of interest.

Funding

None.

\section{Acknowledgments}

Members of the FISMAD Lombardy COVID-19 Impact on Anesthesiologis-Assisted Endoscopy Study Group: Roberto Grassia, Gastroenterology and Digestive Endoscopy Unit, ASST Cremona, Cremona, Italy; Aurora Giannetti, Digestive Endoscopy Unit, IRCCS Multimedica Sesto San Giovanni, Milan, Italy; Francesco Broglia, Digestive Endoscopy and Gastroenterology Unit, ASST Lodi, Lodi, Italy; Paolo Giorgio Arcidiacono, Biliopancreatic Endoscopy and Endoscopic Ultrasonography Unit, IRCCS San Raffaele Hospital, Milan, Italy; Mauro Ghirardi, Digestive Endoscopy Service, Istituto Clinico Città di Brescia, Brescia, Italy; Kareem Khalaf, Digestive Endoscopy Unit, Humanitas Research Hospital, Rozzano, Milan, Italy; Fabio Chicco, Digestive Endoscopy Unit, Voghera and Vigevano Hospitals-ASST Pavia, Pavia, Italy; Mario Gatti, Gastroenterology and Digestive Endoscopy Unit, 
ASST Brianza, Carate Brianza, Monza-Brianza, Italy; Thomas Togliani, Digestive Endoscopy Unit, Carlo Poma Hospital-ASST Mantova, Mantova, Italy; Marco Parravicini, Gastroenterology Unit, ASST Settelaghi, Varese, Italy; Stefano Bargiggia, Endoscopy and Gastroenterology Unit, San Carlo Clinic, Paderno Dugnano, Milan, Italy; Massimiliano Mutignani, Digestive and Interventional Endoscopy Unit, ASST Grande Ospedale Metropolitano Niguarda, Milan, Italy; Lorella Fanti, Digestive Endoscopy Unit, IRCCS San Raffaele Hospital, Milan, Italy; Luca Ferraris, Gastroenterology Unit, ASST Valleolona, Gallarate, Varese, Italy; Rocco Putignano, Gastroenterology and Digestive Endoscopy Unit, ASST Ovest Milanese, Legnano, Milan, Italy; Vincenzo Occhipinti, Digestive Endoscopy and Gastroenterology Unit, Manzoni Hospital-ASST Lecco, Lecco, Italy; Loretta Amato, Gastroenterology and Digestive Endoscopy Unit, ASST Melegnano-Martesana, Melzo, Milan, Italy; Stenio Rosato, Digestive Endoscopy Unit, ASST Valcamonica, Esine, Brescia, Italy; Elia Armellini, Gastroenterology Unit, ASST Bergamo Est, Seriate, Bergamo, Italy; Ivana Zappa, Digestive Endoscopy Service, Minimally Invasive Surgery Division, ASST Lariana, Cantù, Como, Italy; Francesca Boni, Digestive Endoscopy Unit, ASST Melegnano-Martesana, Vizzolo Predabissi, Milan, Italy; Alessandro Longhini, Digestive Endoscopy Unit, ASST Valtellina e Alto Lario, Sondrio, Italy; Gianni Santo Mezzi, Digestive Endoscopy Unit, ASST Brianza, Vimercate, Monza-Brianza, Italy; Guido Missale, Digestive and Interventional Endoscopy Unit, ASST Spedali Civili, Brescia, Italy; Giuseppe Di Flumeri, Digestive Endoscopy Unit, ASST Franciacorta, Chiari, Brescia, Italy; Giuseppe De Roberto, Digestive Endoscopy Unit, European Institute of Oncology, Milano, Italy; Federico De Grazia, Digestive Endoscopy Unit, IRCCS Policlinico San Matteo Foundation, Pavia, Italy; Licia Snider, Gastroenterology and Digestive Endoscopy Unit, ASST Lariana, Como, Italy; Paola Fontana, Digestive Endoscopy Unit, ASST Ovest Milanese, Magenta, Milan, Italy; Roberto Penagini, Gastroenterology and Digestive Endoscopy Unit, IRCCS Ca' Granda Ospedale Maggiore Policlinico Foundation, Milano, Italy; Benedetto Mangiavillano, Digestive Endoscopy Unit, Humanitas Mater Domini, Castellanza, Vvarese, Italy.

We are grateful to Dr. Kareem Khalaf for reviewing the English language of our manuscript.

\section{Author Contributions}

Conceptualization: Calcedonio Calcara ${ }^{1}$

Data curation: $\mathrm{CC}^{1}$, Camilla Ciscato $^{2}$, Arnaldo Amato $^{1}$, Andrea Anderloni ${ }^{2}$

Formal analysis: $\mathrm{CC}^{1}, \mathrm{CC}^{2}, \mathrm{AA}^{1}, \mathrm{AA}^{2}$, Emanuele Sinagra

Investigation: $\mathrm{CC}^{1}$

Methodology: $\mathrm{CC}^{1}$

Supervision: Costanza Alvisi, Sandro Ardizzone, Pietro Gambitta

Validation: CA, SA, PG

Visualization: ES, CA, SA, PG

Writing-original draft: $\mathrm{CC}^{1}, \mathrm{CC}^{2}, \mathrm{AA}^{1}, \mathrm{AA}^{2}, \mathrm{ES}$

Writing-review\&editing: $\mathrm{CC}^{1}, \mathrm{CC}^{2}, \mathrm{AA}^{1}, \mathrm{ES}, \mathrm{CA}, \mathrm{SA}, \mathrm{AA}^{2}, \mathrm{PG}$

\section{ORCID}

Calcedonio Calcara
Camilla Ciscato
Arnaldo Amato
Emanuele Sinagra
Costanza Alvisi
Sandro Ardizzone
Andrea Anderloni
Pietro Gambitta

https://orcid.org/0000-0002-7555-5380 https://orcid.org/0000-0003-1562-1195 https://orcid.org/0000-0002-4397-4142 https://orcid.org/0000-0002-8528-0384 https://orcid.org/0000-0002-0014-5117 https://orcid.org/0000-0001-9915-2992 https://orcid.org/0000-0002-1021-0031 https://orcid.org/0000-0003-0960-1681

\section{REFERENCES}

1. Maida M, Sferrazza S, Savarino E, et al. Impact of the COVID-19 pandemic on gastroenterology divisions in Italy: a national survey. Dig Liver Dis 2020;52:808-815.
2. Repici A, Pace F, Gabbiadini R, et al. Endoscopy units and the coronavirus disease 2019 outbreak: a multicenter experience from Italy. Gastroenterology 2020;159:363-366.e3.

3. Manes G, Repici A, Radaelli F, Bezzio C, Colombo M, Saibeni S. Planning phase two for endoscopic units in Northern Italy after the COVID-19 lockdown: an exit strategy with a lot of critical issues and a few opportunities. Dig Liver Dis 2020;52:823-828.

4. Boškoski I, Pecere S, Bove V, Barbaro F, Perri V, Costamagna G. Impact of SARS-CoV-2 on a high volume endoscopy center in Italy. Dig Liver Dis 2020;52:819-822.

5. ASA Physical Status Classification System [Internet]. Schaumburg: The American Society of Anesthesiologists; c2020 [cited 2021 Oct 22]. Available from: https://www.asahq.org/standards-and-guidelines/asa-physical-status-classification-system.

6. 2019 DGR Regione Lombardia DELIBERAZIONE Nº XI / 1865 Seduta del 09/07/2019. [Internet]. Regione Lombardia. [updated 2019 Jul 9; cited 2021 Jul 31]. Available from: https://www.asst-monza.it/documents/492169/0/DGR+n_XI_1865+del+2019+temoi+d\%27attesa. pdf/95d2f917-8781-e793-a3df-97ba2e926c77

7. Gralnek IM, Stanley AJ, Morris AJ, et al. Endoscopic diagnosis and management of nonvariceal upper gastrointestinal hemorrhage (NVUGIH): European Society of Gastrointestinal Endoscopy (ESGE) guideline update 2021. Endoscopy 2021;53:300-332.

8. Birk M, Bauerfeind P, Deprez PH, et al. Removal of foreign bodies in the upper gastrointestinal tract in adults: European Society of Gastrointestinal Endoscopy (ESGE) clinical guideline. Endoscopy 2016;48:489-496.

9. Oakland K, Chadwick G, East JE, et al. Diagnosis and management of acute lower gastrointestinal bleeding: guidelines from the British Society of Gastroenterology. Gut 2019;68:776-789.

10. de Franchis R, Baveno VI Faculty. Expanding consensus in portal hypertension: report of the Baveno VI consensus workshop: stratifying risk and individualizing care for portal hypertension. J Hepatol 2015;63:743752.

11. Enestvedt BK, Eisen GM, Holub J, Lieberman DA. Is the American Society of Anesthesiologists classification useful in risk stratification for endoscopic procedures? Gastrointest Endosc 2013;77:464-471.

12. Laffin AE, Kendale SM, Huncke TK. Severity and duration of hypoxemia during outpatient endoscopy in obese patients: a retrospective cohort study. Can J Anaesth 2020;67:1182-1189.

13. Elphick DA, Donnelly MT, Smith KS, Riley SA. Factors associated with abdominal discomfort during colonoscopy: a prospective analysis. Eur J Gastroenterol Hepatol 2009;21:1076-1082.

14. Analgo-sedazione in endoscopia digestiva [Internet]. Roma: SIAARTI; c2020 [cited 2021 Oct 22]. Available from: https://www.siaarti.it/ news/338126.

15. Sidhu R, Turnbull D, Newton M, et al. Deep sedation and anaesthesia in complex gastrointestinal endoscopy: a joint position statement endorsed by the British Society of Gastroenterology (BSG), Joint Advisory Group (JAG) and Royal College of Anaesthetists (RCoA). Frontline Gastroenterol 2019;10:141-147.

16. ASGE Standards of Practice Committee, Early DS, Lightdale JR, et al. Guidelines for sedation and anesthesia in GI endoscopy. Gastrointest Endosc 2018;87:327-337.

17. Manes G, Saibeni S, Pellegrini L, et al. Improvement in appropriateness and diagnostic yield of fast-track endoscopy during the COVID-19 pandemic in Northern Italy. Endoscopy 2021;53:162-165.

18. Salerno R, Conti CB, De Silvestri A, Campbell Davies SE, Mezzina $\mathrm{N}$, Ardizzone S. The impact of covid-19 pandemic on urgent endoscopy in Italy: a nation-wide multicenter study. Scand J Gastroenterol 2020;55:870-876.

19. Marco AP. Anesthesiology, the tragedy of the commons, and COVID-19. Anesth Analg 2020;131:120-123.

20. Silva DS. Ventilators by Lottery: The least unjust form of allocation in the coronavirus disease 2019 pandemic. Chest 2020;158:890-891.

21. Rosenbaum L. Facing Covid-19 in Italy - ethics, logistics, and therapeu- 
tics on the epidemic's front line. N Engl J Med 2020;382:1873-1875.

22. Emanuel EJ, Persad G, Upshur R, et al. Fair allocation of scarce medical resources in the time of covid-19. N Engl J Med 2020;382:2049-2055.

23. Hyder AA. Allocating medical resources in the time of covid-19. N Engl J Med 2020;382:e79.

24. Liddell K, Martin S, Palmer S. Allocating medical resources in the time of covid-19. N Engl J Med 2020;382:e79.

25. Firth P, Eyal N. Allocating medical resources in the time of covid-19. N Engl J Med 2020;382:e79.

26. Supady A, Brodie D, Curtis JR. Ten things to consider when implementing rationing guidelines during a pandemic. Intensive Care Med 2021;47:605-608.

27. Vergano M, Bertolini G, Giannini A, et al. Clinical ethics recommendations for the allocation of intensive care treatments in exceptional, resource-limited circumstances: the Italian perspective during the COVID-19 epidemic. Crit Care 2020;24:165.

28. Vanella G, Capurso G, Boškoski I, et al. How to get away with COVID-19: endoscopy during post-peak pandemic. A perspective review. Therap Adv Gastroenterol 2020;13:1756284820965070.

29. Coronavirus in Lombardia, tutti gli aggiornamenti in diretta. [Internet]. Milano: Lombardia Notizie Online. [updated 2021 Apr 1, cited 2021 April 1] Available from: https://www.lombardianotizie.online/coronavirus-in-lombardia-i-dati-di-aprile-2020/

30. Coronavirus in Lombardia, tutti gli aggiornamenti in diretta. [Internet]. Milano: Lombardia Notizie Online; c2020 [cited 2021 October 24]. Available from: https://www.lombardianotizie.online/coronavirus-lombardia-novembre-2020 